\title{
The culture of immanence in the re-use of revival architecture: a new life for Tafuri Castle in Sicily (Portopalo di Capo Passero, Syracuse, Italy)
}

\author{
F. Cantone \\ University of Catania, SDS of Architecture in Syracuse, Italy
}

\begin{abstract}
Cultures of immanence identify areas of sociality, dividing them into the different social groups. These spaces are dictated by rules of appearance, of expressing their strength in economic terms and as regards tradition. 'Medieval revival' and the rediscovery of castles should be seen in this context. In fact, between the late nineteenth and early twentieth centuries, historicism was beyond doubt highly valued and led to the construction of castles and fortresses. These buildings were emblematic of the great desire to embrace the values of a simultaneously romantic and syncretic past.

Processes involved in the regeneration of cities and the urban environment see the reuse of buildings through actions dictated by social needs related to work, education, participation and the public sphere. In this sense, restoration must interpret the site as an instrument that steers the planning process towards balanced decisions: the site as a space of life and living... a characterising element of the project.

The re-use project for Tafuri Castle, located in the southernmost area of Sicily, is set in this context. This work was undertaken by Severino Crott, a famous Florentine architect close to historicism. Partially built in 1935, the castle was only completed at the start of the 1960s and was later transformed into a hotel and used until the late 1990s.

The intention is to return it to the community as a landmark for the area, accurately recovering its technical elements and defining functions related to the specificity of contemporary society and the territory.

Keywords: regeneration process, bottom up, re-use, revival architecture, castle.
\end{abstract}




\section{Introduction: the culture of immanence}

In architecture, culture of immanence can define buildings created for appearance to promote an ancient or new power, repeating it, and to express a declining social status; they coincide with "a world of immanence that is precisely such insofar as those who create it, intend to perpetuate it for as long as possible, seeking exactly there the reasons for their becoming" [1].

Immanence is intended as that which can be determined within a given scope... a concept that can be applied to a society, a culture, a tradition. Based on this consideration, the main "characteristic of cultures of immanence is a strong, solid relationship... between identity and alterity, between event and structure" [1]. It can partly be identified in the concept of habitus, which Pierre Bourdieu defines as "a system of spiritual dispositions for being and doing... a desire to be, that in a certain way, seeks to create the conditions for achieving one's objective" [2].

In other words, in cultures with different social levels, the mechanisms of everyday life and administration are related to the position adopted based on the represented level, producing a distorted reality.

\section{Eclectic historicism in Sicily}

Historicism and interest in the scientific world that the age of Enlightenment inspired, led to a gradual appreciation of medieval art during the subsequent Romantic era. An era in which, the fundamental styles of the past would take shape and identify a strong correlation between art and society; a medieval style that would later be considered a model of modern living [3, p. 97]. The different forms of this cultural mindset will address the multiplicity of expressive registers adopted and the ability to bring together various aspects of nature in a small space. Architectural eclecticism of the era led to the realisation of numerous works throughout Europe, whereas in Italy, it mainly gained ground to complete creations in gothic 'period style'.

These are the cultural bases from which neo-medievalism was to evolve in the second half of the nineteenth century; a neo-medievalism that led to an architectural idea, regenerated in every aspect, not only in terms of style, but also in a grammatical approach to the construction details and design rules [3, p. 185], as well as being based on new techniques. In the book entitled 'Architettura del Medio Evo in Italia' [Architecture of the Middle Ages in Italy], Boito [4] describes the construction of great cathedrals as a basis for re-framing architecture, and extrapolates the foundations for the future; modest medieval building ethics formed the basis for a singular national style in the construction and reconstruction of all kinds of buildings, from castles to museums. Again, Boito's understanding of the building system, for all architectural works, is based on two elements: the first, what we today call 'the resistant system', combines the static qualities of the building, the natural, morphological and geological properties of the soil, the quality of the materials used, building science principles and code requirements; the second concerns the expressive potential of an architectural 
work and its beauty. This combined with function, generates such an architecture and represents its cultural and artistic character [5].

Late examples of these concepts still remain in the stylistic revival of patrician houses... symbol of a slowly declining strength.

\section{Regeneration processes}

The regeneration of a site is often based on the ability to see beyond, to foresee possible re-qualification scenarios, to identify attractions and attractors for local residents, visitors and tourists alike.

"Urban regeneration cannot take place without actions and policies that recognise the basic right of citizens to satisfy their fundamental needs: work, education, health, housing, participation in the public sphere and the recognition of different cultural identities" [6].

Today, in fact, a close and sensitive study cannot be accomplished without an integrated knowledge system that revolves around investigation into human needs; a social component that restores such needs in their entirety through a bottom-up approach based on an awareness of all the variables that may be influenced, therefore providing a broader view.

The bottom-up approach, developed through the Project Cycle Management Method (PCM) of the European Commission - EuropeAid [7], has greatly influenced the European approach to urban design. This type of approach, which is based on the needs of society and involves the key aspects and features of the territory, turns into a re-qualification strategy that enables greater urban



Figure 1: 1935, Severino Crott, original project, private archive. 
regeneration. The main focus is on human value, a capacity for psychological aggregation, the becoming united again and building a structure of stable and shared relations [8] for an economically sustainable architecture. The components of this process can be found in the characteristics of the surroundings and in the spirit of close persons. This is how the social component suddenly gains importance and determines the options of re-qualification. A design process that starts from within the community, unites memory, identity and innovation in a systemic and strategic vision.

\section{The Castle}

The urban regeneration of an immanent culture, clearly expressed in the stylistic revivals of the early twentieth century, is applied to a case study, a building constructed in the form of a castle, datable to 1935. Tafuri Castle stands on a steep cliff on the south-eastern coast of Sicily, opposite the island of Capo Passero in the province of Syracuse, Sicily.

Built by the noble family of Bruno di Belmonte, who brought work and prosperity to the area, the castle marks the border with the district municipality of Portopalo di Capo Passero. Set against a crystal clear blue sea, it is perhaps the most prominent attraction in the area. For many years it has been the symbol of this small fishing village, today a destination for tourists and surfers.



Figure 2: Localization of Tafuri castle in Sicily.

The history of the castle has been almost completely reconstructed.

Initially, the construction of a castle-style villa on behalf of Franzo Bruno di Belmonte was entrusted to the engineer/architect Carmelo Arezzo Trifiletti from Ragusa (of which some sketches are preserved). A substantial exchange of correspondence between Bruno and the company appointed for the construction work later led to the decision to choose precisely Severino Crott from Florence as the new designer.

Severino Crott (Castiglion Fiorentino, 1886-1972) worked in Sicily for the first and only time, whereas he was well known in the fascist circles of Florence. Crott trained at the Arti Decorative di Santa Croce [School of Decorative Arts of Santa 
Croce] in Florence. He studied architecture at the local Academy of Fine Arts, and in 1912 obtained a diploma in architecture in Bologna. The qualities of this skilled draughtsman enabled him to work at the Coppedè studio. During his career as an architect he carried out numerous extension projects for religious buildings, period style extension work, reconstruction projects for churches with strong features from the Gothic and Romantic eras, all located in Tuscany, the design and construction of a church in Patras (Greece) and a villa in the province of Syracuse [10] in the form of a Romanesque castle.

In March 1933, on the initiative of Marquis Franzo, construction work began on castle; Crott the architect only visited Portopalo once as the work and decisions were made by Corrado Consales di Portopalo, the owner of the company who partially completed the work in August 1935 [10].



Figure 3: Aerial photo of the castle, after the purchase of Tafuri.

"This impressive architecture is built on three levels and has a complex volume with corner turrets and a central tower. With its turreted features, this complex building is deliberately designed to evoke the image of a castle, and is underlined by an abundance of elements taken from the mythical repertoire of the Middle Ages. Reinvented but fascinating, its mullioned windows, arrow slits, battlements, brackets and barbicans would have created a menacing appearance to this unique architectural work had it not been for certain details that reveal the peaceful nature of this bourgeois home. Details such as the elegance of the two-tone colour combination given by white stone and brick, or the breezy polygonal loggia open to the sea and a kind of gigantic bow window that links the building to the best modernist tradition" [11]. 
The building structure with its imposing walls of white stone clad with red brick became the property of the Tafuri in 1957 . The family oversaw completion of the property and from 1964 to 1998 it was used as tourist accommodation. The building, which has been closed since 1998, is in ruins and has become the property of and for anyone. Vandals, thieves, destruction, bullying and the trespassing on private property have made this area a sort of space open to anyone and anything, the barriers of which, although repeatedly installed, have not stopped these despicable individuals from invading the area.

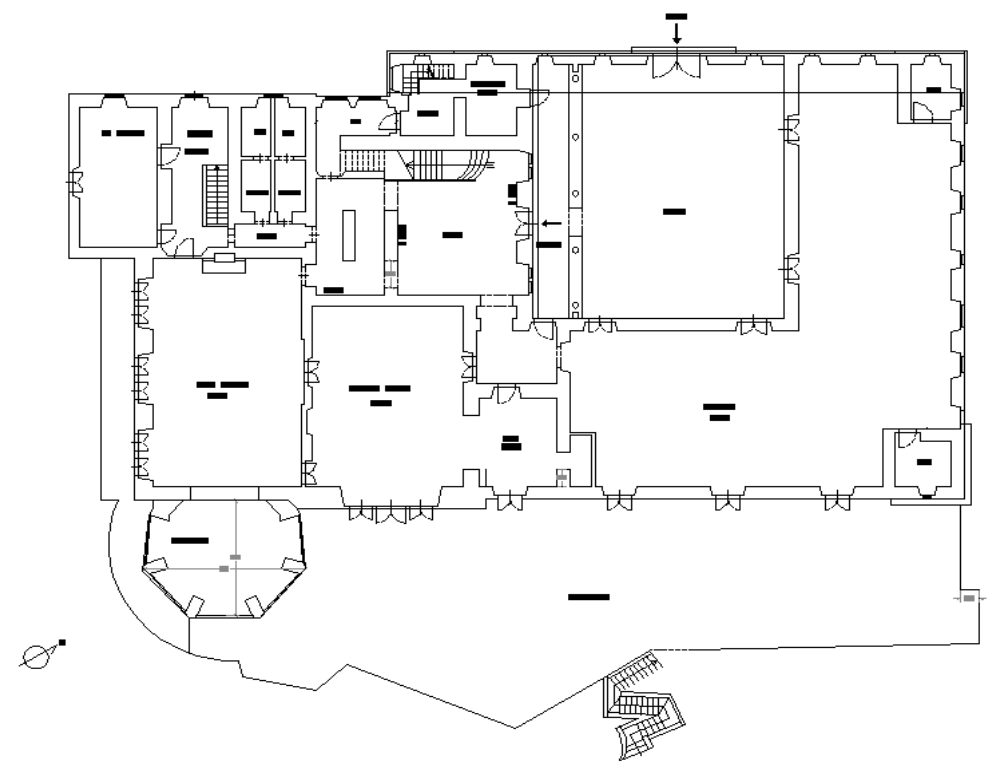

Figure 4: Plan view.

\section{A social and technological project}

The re-qualification project for Tafuri Castle, an expression of a society of immanence and a symbol of eclecticism, still in vogue in the early twentieth century, was initiated on the will of the owners who wished to change the current situation. Tired of the havoc being caused, the destruction, the savage vandalism and the huge costs incurred over the years, they decided to appoint this studio to return the castle to its former splendour, to the territory and to a use.

The research project is based on the considerations previously mentioned, and took into account the immanent characteristics of the structure, the visual and perceived impact of the castle on visitors, the capacities for its use and the potential for economic development of the area. The topic was covered by incorporating other disciplines such as sociology, economics and anthropology in order to break the dichotomy between citizens' problems, the uncontrolled usage of the area and the needs of the owners. 

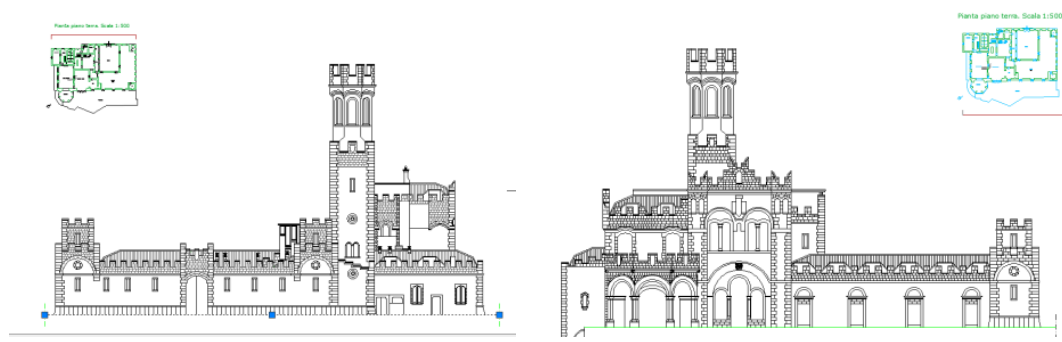

Figure 5: Western and eastern prospect by arch Gabriella Murgana.

The first concept, of a social nature, took into consideration 'proximity'. "The community has for centuries represented a social fabric that is strongly rooted in a territory with distinctive features, but at the same time open to new ideas and diversity. ... a territory that felt the need for co-existence and relations based on a shared project" [12]. Proximity is the instrument through which to restore the centrality of man in society; it becomes a search for co-existence and comparison, with the same values given by Aristotle to the concepts of political and public dimension. The question of giving the collective dimension centrality and opportunity of expression, free from manipulation, ideologies exclusively relating to the past, and exploitation, leads to efficiency and equity, to the common good, to community and to values that are strongly present in the rest of Europe.

Restoring civic responsibility, the sense of belonging and pride in one's heritage are fundamental elements that shape the process. In the second age of globalisation, the strategy must embrace the think locally, act globally approach. This drove research to raise awareness of the territory, to involve the inhabitants and to develop the strong roots that characterise the local area. A beginning from the roots, memory and identity to develop a strength, not only local but global. In this sense, what is the area asking?

Below are the answers research revealed through interviews and meetings with both privileged and underprivileged individuals.

The model applied compared the objectives identified by the citizens (underprivileged individuals) and those set by the town administration (privileged individuals) for establishing a shared policy as regards attractions. The ideal related to regenerating the castle and opening it to the public is common to all the individuals, but the ideas for solutions were muddled, the foundations of which are to be found in a lack of awareness by the users/respondents. The municipal technicians on the other hand were highly sensitive towards matters regarding the castle.

The economic factor, another fundamental element, identifies in the study of the territory, in the confluence and crossing of ideas and in community participation, the uniqueness and inimitability of a specific geographic area; elements of differentiation able to generate a strong competitive advantage [13]. In the collective imagination, the castle appears as a tourist landmark since it was used for many years as a holiday facility. On the other hand, the latest research in 




Figure 6: Methodological scheme of multidisciplinary approach.

the tourism sector affirms that the future of accommodation facilities lies in complexity, in solutions that are best suited to multiple tourist categories. Recent studies have shown that the future of small and medium-sized tourism companies lies in 'collaborative tourism' and in that of small and medium centres that offer cultural and interpersonal exchange opportunities. "A small territory differs from a traditional tourist destination, mainly because of its fragile social structure, as well as for a number of difficulties due to conditions of marginality, which in many cases, inevitably lead to depopulation and the abandonment of the area. Sufferance due to a feeling of unimportance and a total lack of interest towards enhancing the resident experience in terms of development seems to hamper the chances of emerging" [13].



Figure 7: View of castle. 
Subsequent to these assumptions, a re-use compatibility assessment was performed [14] using the instruments of the department of Tecnologie del Recupero Edilizio [Technologies for the recovery of buildings], hence the decision to build a Residenza Turistico Alberghiera - RTA [Hotel and tourism facilities].

This intervention offers many advantages: the first regards the project, which is less invasive compared to others as the current distributed lay-out is maintained and only minor changes are foreseen, changes that economically make all the difference; the second concerns the recent XIX Report on Italian tourism presented in Genoa, which emphasised a growth in tourism between 2000 and 2012 of 12$13 \%$, especially in small towns and in areas with a high impact on landscape and nature. This document identifies the main driving force for the development of tourism in small towns.

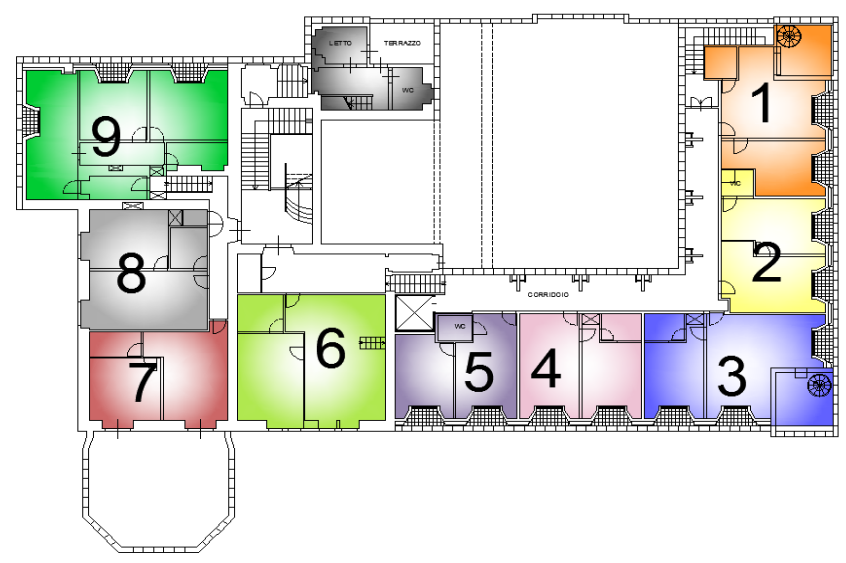

Figure 8: Project of RTA, first floor.

The regeneration project also included data on economic and social values as well as on the potential for tourism in order to produce a re-qualification project designed and sized to the actual capacities of the territory. This led to participation in a public call for the establishment, re-qualification and expansion of local accommodation supply and related completion works through activation of an aid scheme pursuant to art. 75 of Regional Law no. 32 dated 23.12.2000 as replaced by art. 18 of Regional Law No. 9 dated 06.08.09, in favour of small and mediumsized companies operating in the tourism sector in Sicily.

The project is included in the list pending the Regional Decree. 


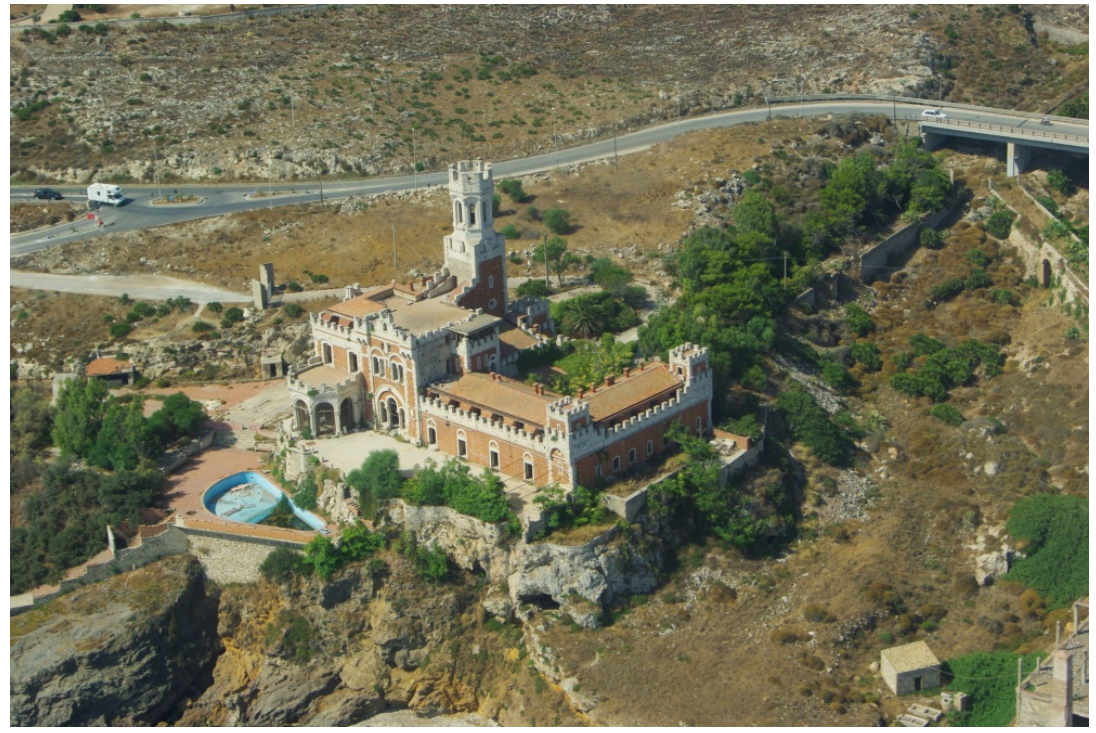

Figure 9: Contemporary aerial view by Giuseppe Blundo.

\section{Conclusions}

The interdisciplinary contributions of a social, economic, technological and anthropological nature have enabled the implementation of a project that leaves no space for improvisation. Based on the needs of the territory, from which it has drawn inspiration, it calls the population to intervene, it respects the ideas of all individuals and proposes building regeneration scenarios that will have an important impact on the entire urban environment.

\section{References}

[1] Augé, M. Che fine ha fatto il futuro?, Milano: Eleuthera, pp. 21-22, 2010.

[2] Bourdier, P. Meditazioni pascaliane, Milano: Feltrinelli, 1998.

[3] Bertelli, Briganti, Giuliano (eds), Storia dell'Arte Italiana, Milano: ElectaBruno Mondadori, vol. IV, 1986.

[4] Boito, C. Architettura del Medio Evo in Italia, Milano: Ulrico Hoepli, 1880.

[5] Cfr. Zucconi, G. L'invenzione del passato: Camillo Boito e l'architettura neomedievale 1855-1890. Venezia: Marsilio, 1987.

[6] Vicari Haddock, S. Moulaert, F. Rigenerare la città. Pratiche di innovazione sociale nelle città europee, Bologna: Il mulino, p. 7, 2009.

[7] Casciaro, A. Progettazione partecipata e strategie attrattive per i centri storici. In: Casciaro, A. Castagneto, F. Processi inclusivi di riqualificazione urbana. Siracusa: Lettera Ventidue, p. 43, 2013.

[8] Morace, F. Santoro, B. Italian factor. Moltiplicare il valore di un paese. Milano: Egea, p. 26, 2014. 
[9] Isola, G. Cozzi, M. Nuti, F. Carapelli, G. (eds) Edilizia in Toscana fra le due guerre. Firenze: Edifir, p. 221, 1995.

[10] Cernigliaro, C. Portopalo di Capo Passero: storia, costumi, tradizioni. Modica: SETIM, p. 136, 1996.

[11] Dainotto, D. Itinerario X. Un Liberty tra grandioso e popolare. In: Quartarone, C. Sessa, E. Mauro, E. Arte e Architettura Liberty in Sicilia. Palermo: Grafill, p. 29, 2010.

[12] Morace, F. Santoro, B. Italian factor. Moltiplicare il valore di un paese. Milano: Egea, p. 92, 2014.

[13] Stroia, P. Strategie collaborative per il turismo in piccoli territori. In: www.costruireturismo.com

[14] Pinto, M.R., Il riuso edilizio, Torino: UTET, pp. 134-140, 2004. 